\title{
DESEMPENHO AGRONÔMICO DA CULTURA DA BATATA EM FUNÇÃO DA APLICAÇÃO DE BORO NO PLANTIO E VIA FOLIAR
}

\author{
Jony Eishi Yuri ${ }^{1}$, Jose Hortencio Mota ${ }^{2}$, Lauro Luis Petrazzini ${ }^{3}$, Fábio Pereira Ribeiro ${ }^{4}$ \\ ${ }^{1}$ Eng. Agrônomo, D.Sc., Embrapa - Centro de Pesquisa Agropecuária do Trópico Semiárido. Petrolina-PE \\ ${ }^{2}$ Professor do curso de Agronomia da Universidade Federal de Goiás - Regional Jataí, Jataí-GO. \\ ${ }^{3}$ Professor do curso de Agronomia da Faculdade Cathedral, Barra do Garças-MT. \\ ${ }^{4}$ Engenheiro Agrônomo, Universidade Vale do Rio Verde, Três Corações- MG.
}

RESUMO: Tem-se constatado que os bataticultores utilizam quantidades elevadas de fertilizantes, sem levar em consideração as exigências nutricionais da cultura, principalmente no tocante aos micronutrientes. Assim, com o objetivo de buscar informações quanto aos benefícios da aplicação de boro na cultura, realizou-se o presente trabalho. $\mathrm{O}$ estudo procurou avaliar as doses de boro (B) aplicadas no plantio e via foliar na cultura. O delineamento experimental foi em blocos casualizados, em esquema fatorial $4 \times 2$, compreendendo quatro doses de B foliar (30,3, 60,6, 90,9, 121,2 $\left.\mathrm{g} \mathrm{ha}^{-1}\right)$ e dois fertilizantes NPK: 04-14-08 com e sem $0,1 \%$ de B em sua formulação, com três repetições. Como fonte de B foliar utilizou-se produto comercial com concentração de $10,1 \%$ de $\mathrm{B}$, sendo as doses estudadas a soma de três aplicações ao longo do ciclo (20, 35 e 50 dias após o plantio). A produtividade total de tubérculos, produtividade de tubérculos tipo "extra" e número total de tubérculos por planta apresentaram efeito significativo apenas para doses de B foliar, ajustando-se ao modelo polinomial de segundo grau. No caso da produtividade de tubérculos do tipo "primeirinha" esta também foi afetada significativamente apenas para o fator doses de B foliar. Os tratamentos não diferiram estatisticamente para o número de tubérculos dos tipos "extra" e "primeirinha". Verificou-se que a adição de $0,1 \%$ de B no fertilizante formulado NPK não trouxe retornos produtivos quando comparado à ausência deste micronutriente. A pulverização foliar nas doses de 73,7 e $77 \mathrm{~g} \mathrm{ha}^{-1}$ de boro proporcionou incrementos na produção de tubérculos de maior tamanho "extra" e produtividade total, respectivamente.

Palavras-chave: Solanum tuberosum. Adubação borratada. Formas de aplicação. Micronutriente.

\section{AGRONOMIC PERFORMANCE OF POTATO CROP IN FUNCION OF BORO IN THE PLANTING AND LEAF APPLICATION}

\begin{abstract}
It has been found that potato producers use large quantities of fertilizers, without taking into account the nutritional requirements of the crop, especially with regard to micronutrients. Thus, in order to obtain information about the benefits of the application of boron in the crop, the present work was carried out. The aim of this study was to evaluate the boron doses (B) applied in planting and foliar via in the crop. The experimental design was a randomized block in factorial scheme $4 \times 2$, comprising four doses of B applied by foliar
\end{abstract}

Cultura Agronômica, Ilha Solteira, v.26, n.2, p.132-141, 2017 
pulverization $\left(30.3,60.6,90.9,121.2 \mathrm{~g} \mathrm{ha}^{-1}\right)$ and two NPK formulated fertilizer: 04-14-08 with $0.1 \% \mathrm{~B}$, and the same fertilizer without $\mathrm{B}$, and three replicates. As a source of $\mathrm{B}$ was used commercial product containing $10.1 \% \mathrm{~B}$, being the doses the sum of three applications throughout the crop cycle (20,35 and 50 after planting). The characteristics total yield of tubers, tuber type "extra" and total number of tubers per plant showed significant effect only for foliar B doses. These showed the same behavior, which was observed as the best adjust a polynomial equation of the second degree. In the case of tuber type "first one" yield this was also affected significantly only by the doses of B. However, it was found by the analysis of the results, a positive linear equation. The characteristics of tubers types "extra" and "first one" did not present significant differences among treatments. It was found that the addition of $0.1 \%$ of B at NPK fertilizer has not brought productive returns when compared to absence of this micronutrient. The foliar pulverization at the doses of 73.7 and $77 \mathrm{~g} \mathrm{ha}^{-1}$ of boron provided increments in the production of larger tubers "extra" and total productivity, respectively.

Key words: Solanum tuberosum. Borated fertilization. Application forms. Micronutrient.

\section{INTRODUÇÃO}

A produção brasileira de batata, em 2014, foi de 3,5 milhões de toneladas, com produtividade média de 27,8 $\mathrm{t} \mathrm{ha}^{-1}$ (IBGE, 2015). As regiões Sul e Sudeste foram responsáveis por $89,5 \%$ desta produção, com destaque para Minas Gerais, o principal estado produtor. Alguns estados têm apresentado produtividades médias acima da média nacional, como o Estado de Goiás com produtividade, em 2014, de 40 t ha $^{-1}$ (AGRIANUAL, 2015). Entretanto, constata-se que para obtenção dessa produtividade, os bataticultores costumam fazer uso de elevadas quantidades de fertilizantes, onerando sobremaneira o custo de produção.

Apesar das grandes diferenças existentes entre as condições climáticas e edáficas nas diversas regiões produtoras de batata, as "recomendações" de adubações empregadas no cultivo desta oleracea no Brasil, geralmente, são muito semelhantes e normalmente tem-se observado o uso de adubos formulados NPK, sendo que o mais comum tem sido o 04-14-08, na quantidade de 4,0 $\mathrm{t} \mathrm{ha}^{-1}$ (MALLMANN et al., 2011).

Muitos dos fertilizantes formulados existentes no mercado, sobretudo a fórmula 04-1408, são acrescidos de micronutrientes, sendo os principais, o zinco ( $\mathrm{Zn}$ ) e o boro (B). No entanto, em razão da diferença de densidade entre as fontes de nutriente e a pequena quantidade presente no formulado, torna-se difícil a aplicação uniforme dos micronutrientes no solo. Maior uniformização de aplicação seria possível, principalmente quando se trata de micronutriente, adotando pulverizações foliares ou até mesmo o tratamento de sementes. De acordo com Mesquita et al. (2007), nos últimos anos, o uso de micronutrientes, principalmente Zn e B, vem aumentando em razão da elevação da produtividade e do emprego de alta tecnologia associados ao cultivo em regiões de baixa fertilidade do solo. Diante desse fato, empresas de fertilizantes têm desenvolvido novos produtos, produzidos com novas 
tecnologias industriais, que podem apresentar melhor eficiência. Entretanto, para verificar a real eficiência destes lançamentos é necessário o desenvolvimento de pesquisas para a validação dos mesmos.

Dentre os micronutrientes, o B tem como característica principal a baixa redistribuição na planta, por isso, os sintomas de deficiência se manifestam nos pontos de crescimento, áreas de diferenciação e órgãos com maior expansão celular (TAIZ; ZEIGER, 2006). Verifica-se a dificuldade prática de se realizar a correção da deficiência desse elemento, que é facilmente lixiviado pela chuva. Esse problema pode ser contornado pelo uso de materiais que absorvam os sais de B, liberando-os lentamente (AHMAD et al., 2012).

Quanto à dinâmica do B no solo, de acordo com Communar e Keren (2007), os mecanismos de adsorção desse elemento podem ser explicados pela adsorção de íon borato, formação de complexos orgânicos, precipitação de boratos insolúveis com alumina e sílica, e entrada do B nas grades cristalinas dos minerais de argila. Assim sendo, em razão dos solos brasileiros serem, geralmente, ricos em caulinita e sesquióxidos de ferro e de alumínio, a adsorção de B constitui-se em fenômeno de grande importância. Deve-se esperar que a correção dos solos até pH em água de 6, como é recomendada para um grande número de culturas, aumente a adsorção do boro adicionado (ROSOLEM; BÍSCARO, 2007).

Entre os micronutrientes, de uma maneira geral, entre as culturas, a deficiência de B é a que ocorre em maior frequência ao lado do zinco (BLEVINS; LUKASZEWSKI, 1998). De acordo com Marschner (1995), o B está relacionado a uma série de processos fisiológicos das plantas tais como: transporte de açúcar; síntese da parede celular; lignificação; estrutura da parede celular; respiração; metabolismos de carboidratos; metabolismos de RNA; metabolismos de ácido indolacético; metabolismos de compostos fenólicos; metabolismo de ascorbato; fixação de nitrogênio; e diminuição da toxidez de alumínio.

Por outro lado, em geral, o excesso de B pode induzir vários distúrbios metabólicos nas plantas, além de provocar a diminuição na quantidade de clorofila e reduzir a atividade fotossintética, afetando assim o crescimento das plantas (LANDI et al., 2012). No Brasil, em trabalho realizado por Mesquita et al. (2007), a maior produtividade total foi obtida com a dose de 4,38 $\mathrm{kg} \mathrm{ha}^{-1}$ de B, quantidade muito superior ao indicado por Fontes (1999), que sugere a adição de $1,1 \mathrm{~kg} \mathrm{ha}^{-1}$ via solo deste micronutriente para o cultivo de batata. Em razão da escassez das pesquisas com boro na cultura da batata, da constante elevação do custo dos fertilizantes e da necessidade de se buscar o uso eficiente dos recursos naturais, tornam-se necessários estudos que comprovem os benefícios da aplicação desse micronutriente na cultura.

Assim, o objetivo deste estudo foi avaliar o efeito do boro adicionado ao formulado NPK no plantio associado ou não a doses desse micronutriente via foliar no desempenho agronômico da cultura da batata.

Cultura Agronômica, Ilha Solteira, v.26, n.2, p.132-141, 2017 


\section{MATERIAL E MÉTODOS}

O experimento foi conduzido na Fazenda Experimental da Universidade Vale do Rio Verde (Unincor), localizada no município de Três Corações-MG entre os meses de maio e setembro de 2008. O solo da área experimental foi classificado como Argissolo Vermelho Amarelo Eutrófico Plíntico, textura argilosa (EMBRAPA, 2013). Os resultados da análise química do solo, conforme metodologia descrita por Ribeiro et al. (1999), foram: $\mathrm{K}=61,0 \mathrm{mg}$ $\mathrm{dm}^{-3} ; \mathrm{P}=8,27 \mathrm{mg} \mathrm{dm}^{-3} ; \mathrm{Ca}=2,2 \mathrm{cmol}_{\mathrm{c}} \mathrm{dm}^{-3} ; \mathrm{Mg}=1,80 \mathrm{cmol}_{\mathrm{c}} \mathrm{dm}^{-3} ; \mathrm{Al}=0 \mathrm{cmol}_{\mathrm{c}} \mathrm{dm}^{-3} ; \mathrm{H}+\mathrm{Al}=$ $3,2 \mathrm{cmol}_{\mathrm{c}} \mathrm{dm}^{-3} ;$ CTC efetiva $=4,16 \mathrm{cmolc} \mathrm{dm}^{-3} ;$ CTC potencial $=7,36 \mathrm{cmolc} \mathrm{dm}^{-3} ; \mathrm{V} \%=$ 56,$5 ; \mathrm{pH}$ em água $=5,8 ; \mathrm{Zn}=1,9 \mathrm{mg} \mathrm{dm}^{-3} ; \mathrm{Fe}=194,6 \mathrm{mg} \mathrm{dm}^{-3} ; \mathrm{Mn}=20,9 \mathrm{mg} \mathrm{dm}^{-3} ; \mathrm{Cu}=2,7$ $\mathrm{mg} \mathrm{dm}^{-3} ; \mathrm{B}=0,4 \mathrm{mg} \mathrm{dm}^{-3}$. Esse teor de B, de acordo com Galrão (2002), é considerado médio.

Os dados de precipitação e temperatura para o município de Três Corações - MG durante a condução do experimento são apresentados na Figura 1, sendo que a precipitação total foi de $36,8 \mathrm{~mm}$ e temperatura mínima, média e máxima de 5,0, 18,3 e $32,7^{\circ} \mathrm{C}$, respectivamente.

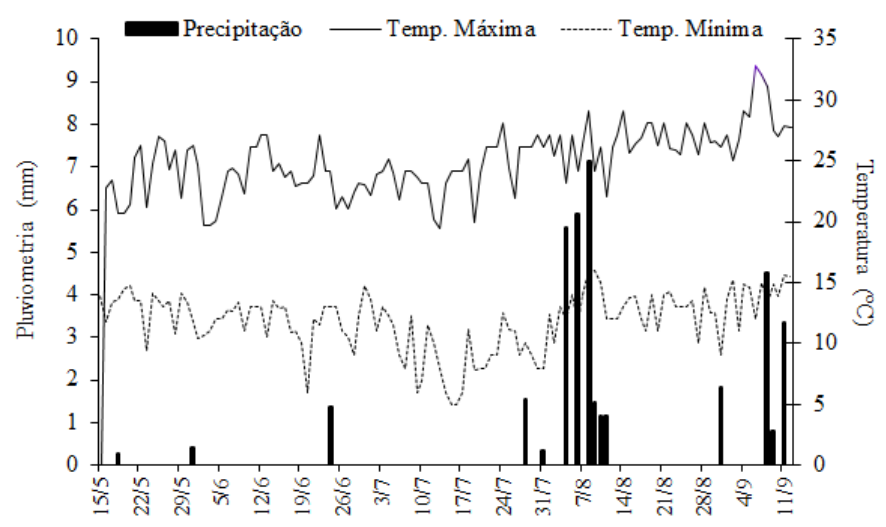

Figura 1. Precipitação pluviométrica e temperaturas máxima e mínima registradas no período de condução do experimento em Três Corações - MG. Fonte: AGRITEMPO (2017).

O delineamento experimental foi o de blocos casualizados, em esquema fatorial $4 \times 2$, compreendendo quatro doses de B foliar (30,3: 60,6: 90,9: 121,2 $\mathrm{g} \mathrm{ha}^{-1}$ ), com e sem este micronutriente $(0,1 \%$ de B) associado ao fertilizante formulado NPK: 04-14-08, em três repetições. Como fonte de B foliar utilizou-se um produto comercial com 10,1\% de B não quelatizado, sendo as doses estudadas a soma de três aplicações ao longo do ciclo, conforme recomendação do fabricante.

A área experimental foi constituída de três blocos com 4 linhas de plantio cada, com $19,2 \mathrm{~m}$ de comprimento. A parcela foi dimensionada com 2,4 $\mathrm{m}$ de comprimento e $3 \mathrm{~m}$ de largura $\left(7,20 \mathrm{~m}^{2}\right)$ e espaçamento de $0,75 \mathrm{~m}$ entre linhas, sendo considerada como área útil a parte central $(0,9 \times 1,5 \mathrm{~m})$ com $1,35 \mathrm{~m}^{2}$.

O preparo do solo ocorreu 30 dias antes do plantio, onde foram realizadas uma subsolagem, uma aração e duas gradagens, de acordo com as recomendações para a cultura da batata, sendo utilizado o sulcador com três hastes, do tipo bico de pato, com capacidade de 
confeccionar sulcos de até $0,3 \mathrm{~m}$ de profundidade, para a realização do plantio. A distância entre cada haste foi previamente regulada em $0,75 \mathrm{~m}$. A adubação foi efetuada manualmente antes do plantio, distribuindo-se o adubo ao longo da base do sulco. Após essa operação, com o auxílio de uma enxada, efetuou-se leve revolvimento com o intuito de evitar o contato direto do adubo com os tubérculos. A quantidade aplicada foi de 4,0 $\mathrm{t} \mathrm{ha}^{-1}$ do formulado 04-14-08 com e sem boro, de acordo com os tratamentos (MALLMANN et al., 2011).

O plantio foi realizado no dia 15/05/2008, com tubérculos-semente da cultivar Vivaldi, adquiridos diretamente de um produtor local, sendo os tubérculos "semeados" manualmente a uma distância de 0,30 m entre tubérculos, depositados cuidadosamente ao longo da base do sulco na profundidade de $0,25 \mathrm{~m}$. Em seguida, com o mesmo sulcador, realizou-se o fechamento dos mesmos.

Logo após o processo de plantio, foi realizada a primeira irrigação e as demais realizadas periodicamente durante todo o ciclo, de acordo com as exigências da cultura, utilizando o método de irrigação por aspersão, salientando-se que a lâmina média foi de aproximadamente $6,0 \mathrm{~mm} / \mathrm{dia}$. A amontoa foi efetuada 20 dias após o plantio. Nesta data tiveram início as aplicações dos tratamentos referentes ao B foliar. As pulverizações foliares, num total de três, foram realizadas no dia da amontoa, 35 e 50 dias após o plantio, com pulverizador manual com 5,0 L de capacidade, em máxima pressão, com volume da calda de $200 \mathrm{~L} \mathrm{ha}^{-1}$ (amontoa), $300 \mathrm{~L} \mathrm{ha}^{-1}$ (aos 35 dias) e de $400 \mathrm{~L} \mathrm{ha}^{-1}$ (aos 50 dias), salientando-se que em todas as aplicações, utilizou-se um espalhante adesivo. Para evitar a ocorrência de deriva, no momento da aplicação, instalou-se ao redor da parcela uma cortina plástica com $1,0 \mathrm{~m}$ de altura.

Os demais tratos culturais e fitossanitários, tais como controle de doenças fúngicas e de insetos praga, foram realizados utilizando os produtos à base de mancozeb, hidróxido de cobre e metamidofós. o dessecamento da cultura foi realizado 103 dias após o plantio com aplicação do herbicida paraquat, na dosagem recomendada pelo fabricante.

Aos 120 dias após o plantio efetuou-se a colheita por meio de arranquio manual e, em seguida, foram avaliadas as seguintes características: produtividade total, número de tubérculos por planta, número e produtividade de tubérculos do tipo "extra" (42 $\mathrm{mm}$ a 70 $\mathrm{mm}$ ), número e produtividade de tubérculos do tipo "primeirinha" (33 a $42 \mathrm{~mm}$ ), seguindo a classificação padronizada pela CEAGESP (2004).

Os dados foram submetidos à análise de variância (teste $\mathrm{F}$ ), sendo as médias comparadas pelo teste de Tukey para B adicionado no plantio na forma de fertilizante formulado NPK e análise de regressão para doses de B aplicado via foliar.

\section{RESULTADOS E DISCUSSÃO}

O resultado da análise de variância para a produtividade total de tubérculos foi significativo para doses de B foliar. O uso da adubação NKP com ou sem B via solo e a sua

Cultura Agronômica, Ilha Solteira, v.26, n.2, p.132-141, 2017 
interação não apresentaram efeitos significativos. Para doses de B observou-se que a máxima produtividade de tubérculos $\left(42,86 \mathrm{t} \mathrm{ha}^{-1}\right)$, foi obtida com o uso de 77,0 $\mathrm{g} \mathrm{ha}^{-1}$ deste micronutriente (Figura 2), salientando-se que as pulverizações com $\mathrm{B}$ foram divididas em três ao longo do ciclo da cultura. No comparativo entre o formulado NPK 04-14-08 com e sem a adição $0,1 \%$ de $\mathrm{B}$ para essa característica constatou-se que no formulado com B a produtividade foi de 36,50 $\mathrm{t} \mathrm{ha}^{-1}$ enquanto a utilização do fertilizante NPK 04-14-08 sem B proporcionou uma média de $33,43 \mathrm{t} \mathrm{ha}^{-1}$.

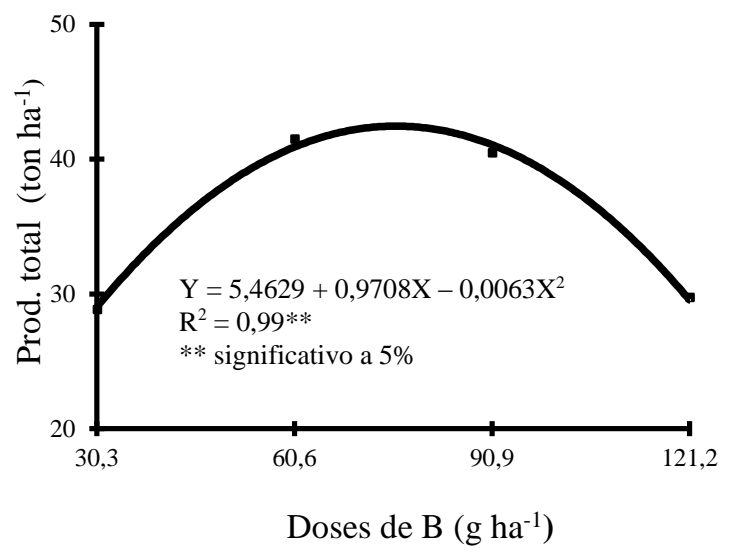

Figura 2. Produtividade total de tubérculos de batata em função de doses de B foliar.

Pelos resultados obtidos infere-se que a formulação com 0,1 \% de B não apresentou respostas positivas na produtividade da batata, provavelmente pela dificuldade na distribuição do adubo na área em função da sua baixa proporção no formulado. Hopkins et al. (2007), avaliando diferentes formas e épocas de aplicação de B na cultura da batata, entre as quais aplicações via solo e também por meio de pulverização foliar, não constataram diferenças significativas entre os tratamentos. Salienta-se que no trabalho destes autores, o teor de B no solo da área experimental era de $1,5 \mathrm{mg} \mathrm{dm}^{-3}$, bem acima do valor observado no presente ensaio, que foi de $0,4 \mathrm{mg} \mathrm{dm}^{-3}$. De acordo com Fageria (2000), teores elevados de B no solo provocam fitotoxidez, sendo necessário conhecer as doses adequadas desse micronutriente. Todavia, no presente trabalho, não foram constatados sintomas de fitotoxidez na parte aérea da planta, apenas redução da produtividade.

Os resultados positivos da adubação com B alcançados no presente trabalho podem estar relacionados ao seu papel funcional no metabolismo de desenvolvimento da batata, uma vez que é considerado essencial para a integridade e funcionamento das membranas celulares (AHMAD et al., 2012).

Resultados similares foram observados na produtividade de tubérculos do tipo "extra", em que ocorreu efeito significativo apenas para as doses de B foliar. O uso do adubo formulado com NPK, com ou sem B e os efeitos da interação não foram significativos. Pela análise da equação de regressão observou-se que os resultados ajustaram-se a uma equação 
polinomial de segundo grau, onde a maior produtividade de $\left(32,98 \mathrm{t} \mathrm{ha}^{-1}\right)$ foi alcançada com a dose de 73,7 $\mathrm{g} \mathrm{ha}^{-1}$ de B (Figura 3), pulverizados três vezes ao longo do ciclo.

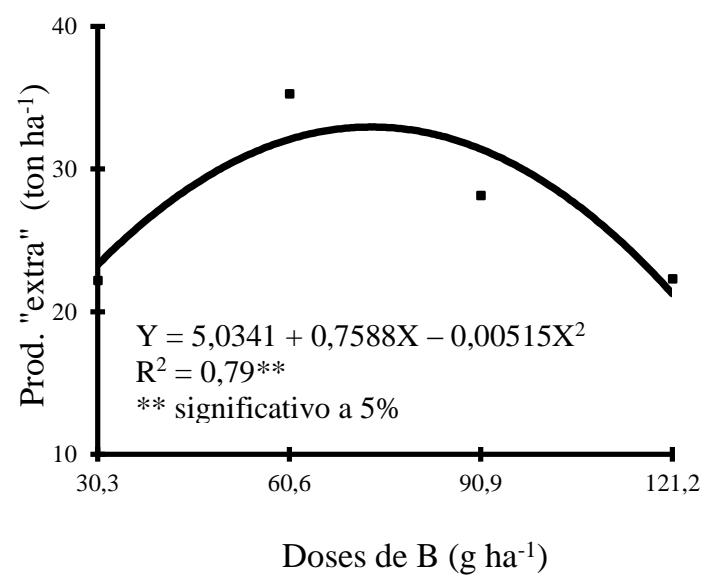

Figura 3. Produtividade de tubérculos do tipo "extra" de batata em função de doses de B aplicado via foliar.

Da mesma forma como observado nas produtividades anteriores, não foi constatada diferença significativa para a aplicação do formulado NPK 04-14-08 com a adição $0,1 \%$ de B para produtividade de tubérculos do tipo "extra". Sendo que o formulado com B propiciou 26,80 t ha ${ }^{-1}$ enquanto a utilização do fertilizante NPK 04-14-08 sem B proporcionou uma média de 27,22 t ha ${ }^{-1}$, não havendo diferenças significativas, e comprovando novamente que o 0,1 \% de B adicionado ao formulado NPK não trouxe retorno em termos de maior produtividade. Mesquita et al. (2007) em estudo em casa de vegetação, com a cultura da batata conduzida em vasos, avaliando doses de B em dois tipos de solo (Latossolo Vermelho e Cambissolo) chegaram a resultado semelhante, com ganhos de produtividade de tubérculos. Salienta-se que neste estudo, os autores aplicaram o equivalente a $4,38 \mathrm{~kg} \mathrm{ha}^{-1}$ de B para a obtenção da maior produtividade, dose bem superior a aplicada no presente estudo. Uma das prováveis causas dessa maior necessidade seja em razão do menor $\mathrm{pH}$ do dois solos utilizados nesse experimento, uma vez que, de acordo com Malavolta (2006), o boro apresenta um comportamento quadrático com o ponto de máxima disponibilização quando o $\mathrm{pH}$ for próximo de 7,0.

A produtividade de tubérculo do tipo "primeirinha" foi afetada significativamente apenas para o fator doses de B foliar, sendo que os valores observados para esta classificação 225 de tubérculos ajustou-se a um modelo de equação linear positiva (Figura 4). No comparativo entre os fertilizantes NPK, foi obtida uma média de 6,02 e 6,73 t ha ${ }^{-1}$ com a aplicação do formulado NPK 04-14-08 com 0,1\% e na ausência de B, respectivamente.

Cultura Agronômica, Ilha Solteira, v.26, n.2, p.132-141, 2017 


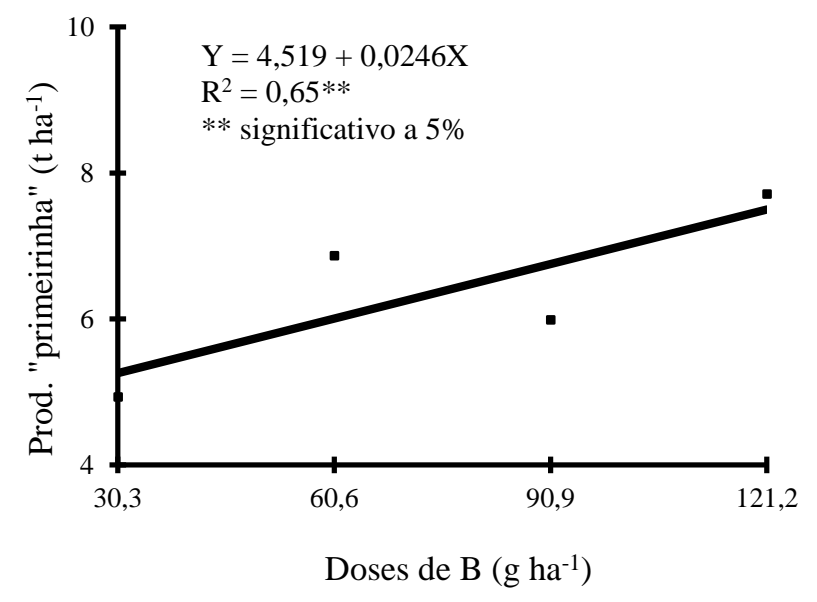

Figura 4. Produtividade de tubérculos do tipo "primeirinha" de batata em função de doses de B aplicado via foliar.

O número total de tubérculos por planta também foi influenciado significativamente apenas pelas doses de B foliar. O maior número de tubérculos por planta (11,1 tubérculos) foi verificado quando se aplicou 82,17 $\mathrm{g} \mathrm{ha}^{-1}$ de B ao longo do ciclo da cultura (Figura 5). Quanto ao comparativo entre o formulado com e sem B, não se constatou diferença significativa.

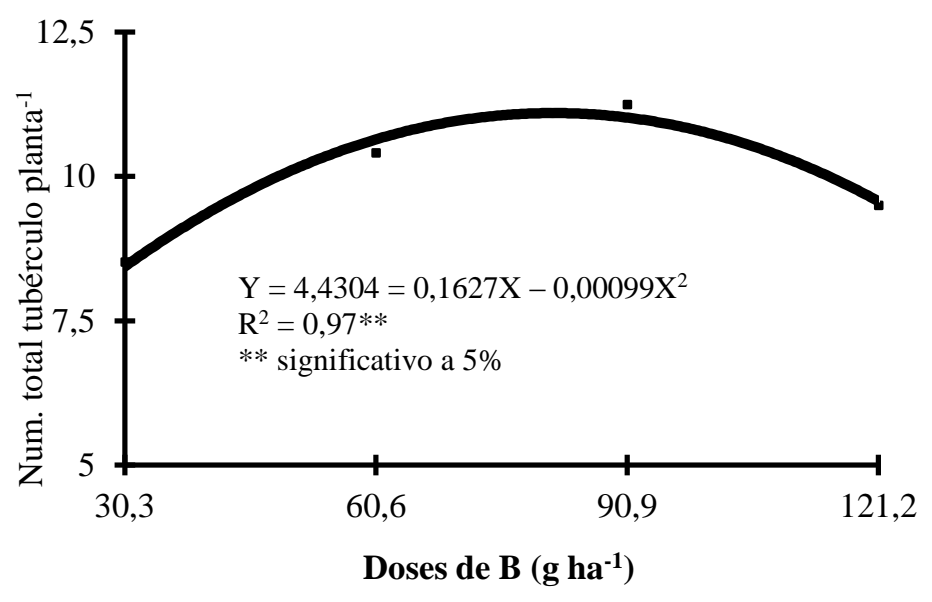

Figura 5. Número total de tubérculos de batata por planta em função de doses de B aplicado via foliar.

De modo semelhante, as características número de tubérculos dos tipos "extra" e "primeirinha" não apresentaram diferenças significativas entre os tratamentos. No comparativo entre os dois formulados NPK (com e sem B), verifica-se que o número de tubérculos do tipo extra, foi de 5,38 e 5,51 tubérculos por planta, respectivamente para o formulado com e sem B. O número total de tubérculos do tipo "primeirinha" apresentou a quantidade de 2,84 tubérculos por planta quando se aplicou o fertilizante formulado com $0,1 \%$ de $\mathrm{B}$, enquanto a aplicação deste mesmo formulado, sem boro proporcionou a produção de 3,22 tubérculos por planta. Tubérculo do tipo "extra" além de serem os mais aceitos pelo Cultura Agronômica, Ilha Solteira, v.26, n.2, p.132-141, 2017 
mercado consumidor, são os de maior valor comercialmente quando comparados aos do tipo "primeirinha". Esses resultados estão em consonância com as informações de Mesquita et al. (2012) que salientam a importância desse micronutriente na cultura da batata, por estar diretamente relacionado com o aumento da produtividade de tubérculos desde que sua aplicação seja na dosagem adequada.

\section{CONCLUSÃO}

O uso de fertilizante formulado NPK enriquecido com $0,1 \%$ de boro não influenciou o desempenho agronômico da cultura da batata quando comparado à ausência do micronutriente.

A pulverização foliar nas doses de 73,7 e $77 \mathrm{~g} \mathrm{ha}^{-1}$ de B, parcelada em três aplicações, proporcionou incrementos na produção de tubérculos de maior tamanho "extra" e produtividade total, respectivamente.

\section{REFERÊNCIAS BIBLIOGRÁFICAS}

AGRIAnUAl. Anuário Estatístico da Agricultura Brasileira 2015. São Paulo: FNP Consultoria e Comércio, 2015. 472 p.

AGRITEMPO Sistema de monitoramento agrometeorológico. Disponível em: <https://www.agritempo.gov.br/agritempo/jsp/PesquisaClima/index.jsp?siglaUF=MG> Acesso em: 25 abr. 2017.

AHMAD, W.; ZIA, M. H.; MALHI, S. S.; NIAZ, A.; ULLAH, S. Boron deficiency in soils and crops: a review. 2012. 39 p. Disponível em: http://www.intechopen.com/books/cropplant/boron-deficiency-in-soils-and-crops-a-review. Acesso em: 15 abr. 2016.

BLEVINS, D. G.; LUKASZEWSKI, K. M. Boron plant structure and function. Annual Review of plant physiology and plant molecular biology, Palo Alto, v. 49, p.481-500, 1998.

CEAGESP. Classificação de batata in natura. 2004. Disponível em: http://www.ceagesp.gov.br/produtor/classific. Acesso em: 02 fev. 2015.

COMMUNAR, G.; KEREN, R. Effect of transient irrigation on boron transport in soils. Soil Science Society of America Journal, Madison, v. 71, n. 2, p.306-313, 2007.

EMBRAPA - Empresa Brasileira de Pesquisa Agropecuária. Centro Nacional de Pesquisa de Solos. Sistema brasileiro de classificação de solos. 3.ed. Rio de Janeiro: EMBRAPA, 2013. $353 \mathrm{p}$.

FAGERIA, N. K. Níveis adequados e tóxicos de boro na produção de arroz, feijão, milho, soja e trigo em solo de cerrado. Revista Brasileira de Engenharia Agrícola e Ambiental, Campina Grande, v. 4, n. 1, p.57-62, 2000.

Cultura Agronômica, Ilha Solteira, v.26, n.2, p.132-141, 2017 
FONTES, P. C. R. Sugestões de adubação para hortaliças. In. RIBEIRO, A. C.; GUIMARÃES, P. T. G.; ALVAREZ, V. H. (Eds). Recomendações para o uso de corretivos e fertilizantes em Minas Gerais: 5 A Aproximação. Viçosa: UFV, 1999. p. 171-174.

GALRÃO, E. Z. Micronutrientes. In: SOUSA, D. M. G.; LOBATO, E. (Ed.). Cerrado: correção do solo e adubação. Planaltina-DF: Embrapa Cerrados, 2002. cap. 8, p. 185-226.

HOPKINS, B.G.; JOLLEY, V.D.; WEBB, B.L.; CALLAHAN, R.K. Boron fertilization in potato. In: WESTERN NUTRIENT MANAGEMENT CONFERENCE, 2007. Proceedings... Reno: IPNI, 2007. p. 215-218. Disponível em: http://ucanr.edu/sites/nm/files/76609.pdf . Acesso em: 09 mar. 2017

IBGE - Instituto Brasileiro de Geografia e Estatística. Levantamento Sistemático da Produção Agrícola. Rio de Janeiro: IBGE, 2015. 81 p.

LANDI, M.; DEGLINNOCENTI, E.; PARDOSSI, A.; GUIDI, L. Antioxidant and photosynthetic responses in plants under boron toxicity: a review. American Journal of Agricultural and Biological Sciences, New York, v. 7, n. 3, p.255-270, 2012.

MAGALHÃES, J. R. Diagnose de desordens nutricionais em hortaliças. Brasília: EMBRAPA CNPH, 1988. 64 p.

MALAVOLTA, E. Manual de nutrição mineral de plantas. São Paulo: Agronômica Ceres, 2006. $638 \mathrm{p}$.

MALLMANN, N.; LUCCHESI, L. A. C.; DESCHAMPS, C. Influência da adubação com NPK na produção comercial e rentabilidade da batata na região Centro-Oeste do Paraná. Revista Brasileira de Tecnologia Aplicada nas Ciências Agrárias, Guarapuava, v. 4, n. 3, p.67-82, 2011.

MARSCHNER, H. Mineral nutrition of higher plants. 2 ed. New York: Academic Press, 1995. 889 p.

MESQUitA, H. A.; AlvarengA, M. A. R.; PAUlA, M. B.; CARVAlHO, J. G.; NÓBREGA, J. C. A. Produção e qualidade da batata em resposta ao boro. Ciência e Agrotecnologia, Lavras, v. 31, n. 2, p.385-392, 2007.

MESQUITA, H. A.; PÁDUA, J. G.; YURI, J. E.; ARAÚJO, T. H. Fertilização da cultura da batata. Informe Agropecuário, Belo Horizonte, v. 33, n. 270, p.52-61, 2012.

RIBEIRO, A. C.; GUIMARÃES, P. T. G.; ALVAREZ V., V. H. Recomendações para o uso de corretivos e fertilizantes em Minas Gerais: $5^{\text {a }}$ aproximação. Viçosa, MG: Comissão de Fertilidade do solo do Estado de Minas Gerais, 1999. 180 p.

ROSOLEM, C. A.; BÍSCARO, T. Adsorção e lixiviação de boro em Latossolo vermelhoamarelo. Pesquisa Agropecuária Brasileira, Brasília, v. 42, n. 10, p.1473-1478, 2007.

TAIZ, L.; ZEIGER, E. Fisiologia vegetal. 3 ed. Porto Alegre: Artmed, 2006. 722 p.

Cultura Agronômica, Ilha Solteira, v.26, n.2, p.132-141, 2017 